\title{
Fluctuating asymmetry in metric traits; a practical example of calculating asymmetry, measurement error, and repeatability
}

\author{
Thea $\varnothing$. Bechshøft ${ }^{1}, 2$ Frank F. Rigét ${ }^{2}$, Øystein Wiig ${ }^{1}$ \& Christian Sonne ${ }^{2, *}$ \\ 1) Natural History Museum, University of Oslo, P.O. Box 1172 Blindern, N-0562 Oslo, Norway \\ 2) Department of Arctic Environment, National Environmental Research Institute, University of \\ Aarhus, P.O. Box 358, DK-4000 Roskilde, Denmark ("corresponding author's e-mail: csh@dmu. \\ $d k)$
}

Received 26 Apr. 2007, revised version received 12 Nov. 2007, accepted 6 Nov. 2007

Bechshøft, T. Ø., Rigét, F. F., Wiig, Ø. \& Sonne, C. 2008: Fluctuating asymmetry in metric traits; a practical example of calculating asymmetry, measurement error, and repeatability. - Ann. Zool. Fennici 45: 32-38.

We present an example of background statistics in studies of fluctuating asymmetry (FA); calculations of asymmetry, measurement error (ME), and repeatability. Nine bilateral metric traits in skulls and lower jaws of 691 East Greenland and Svalbard polar bears (Ursus maritimus) were measured twice, and examined for asymmetry. The skulls were collected in the period 1892-2004. In this study, 2.0\% of the FA data were identified and treated as outliers, which is less than in comparable studies. FA for each trait amounted to $0.1 \%-3 \%$ of the average size of the corresponding trait. The magnitude of FA generally increased with trait size. For every trait measured, ME was found to be smaller than FA. The repeatability of the traits was inversely proportional to ME. Five of the nine traits had a repeatability of $90 \%$ or more, which is similar to what has been reported in other studies.

\section{Introduction}

Fluctuating asymmetry (FA) refers to small, random deviations from the ideal morphological symmetry and is measured as the absolute difference between a trait on the left- and righthand side of a bilaterally symmetrical organism (Møller \& Swaddle 1997, Palmer \& Strobeck 2003a). FA is often taken as a measure of developmental stability (DS), "the ability to attain equal development under the given circumstances" (Zakharov 1992), and its counterpart developmental instability (DI). In principle, DS reflects the organism's ability to buffer its devel- opment against disturbance (Møller \& Swaddle 1997). The more fit the genotype of an organism, and the less stress from the surrounding environment it is exposed to, the higher DS and thus lower FA it is expected to have (Stige 2004). Higher levels of FA have been connected with increased population density (Zakharov et al. 1997), social stress (Valetsky et al. 1997, Gibbs \& Breuker 2006), sexual selection (Mazzi et al. 2003, Voigt et al. 2005), nutritional stress (Pravosudov \& Kitaysky 2006), heat stress (Siegel et al. 1977, Petavy et al. 2006), disease and parasitic stress (Møller 2006), and genetic factors such as increased levels of hybridization and 

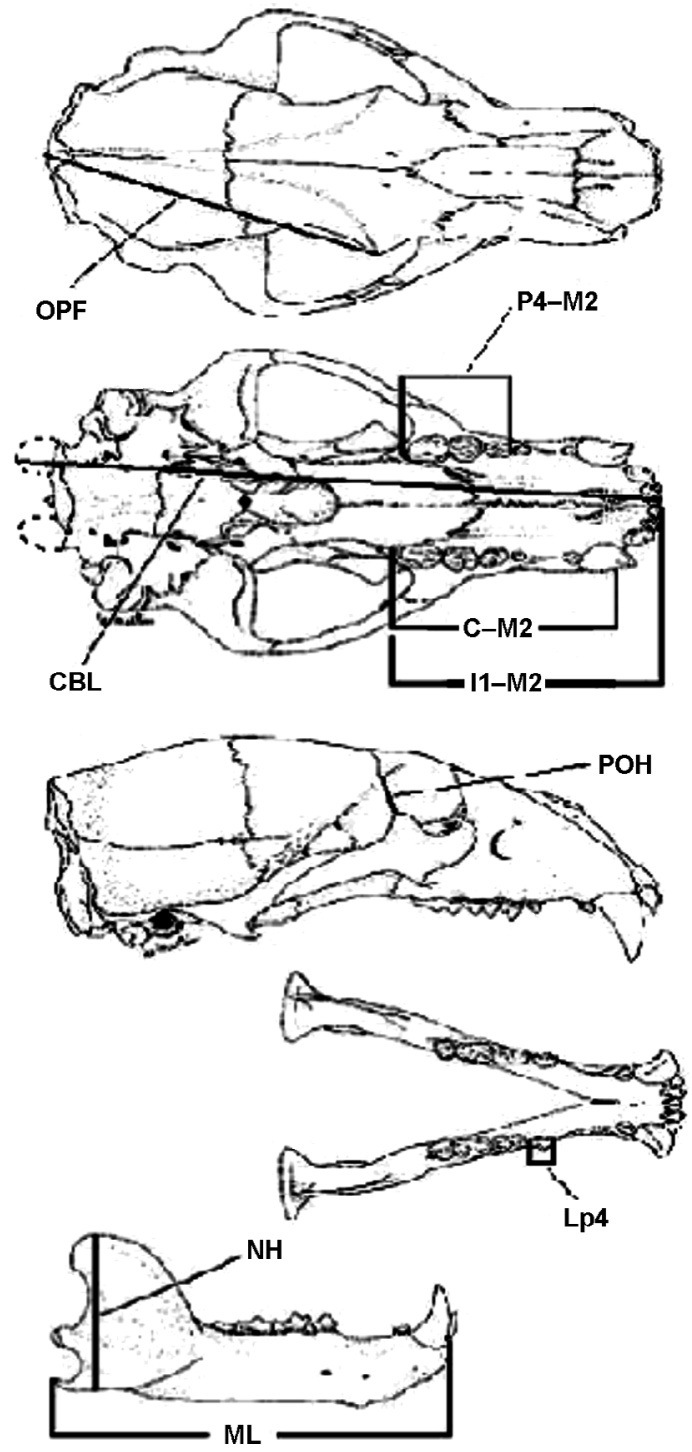

Fig. 1. Nine metric traits (see Table 1) measured on skulls of East Greenland and Svalbard polar bears (Ursus maritimus). Figure modified from Amstrup and DeMaster (1988).

heterozygosity (Borrell et al. 2004, Andersen et al. 2006). FA studies have been conducted on metric and meristic traits of a multitude of organisms (Zakharov \& Yablokov 1990, Blagojevic \& Vujosevic 2004, Vilisics et al. 2005, Andersen et al. 2006, Green \& Lochmann 2006, Pelabon et al. 2006, Bechshøft et al. 2008).

A robust methodology is essential in FA studies to avoid serious flaws in the analyses (Merilä \& Björklund 1995, Stige 2004). One of the greatest challenges in working with FA is getting the measurement error (ME) as small as possible (Merilä \& Björklund 1995, Palmer \& Strobeck 2003a, Stige 2004). Replicate and independent measurements are important, so as to be able to distinguish between FA and ME in the analyses (Palmer 1994, Merilä \& Björklund 1995, Palmer \& Strobeck 2003a). Replicate measurements of the chosen traits provide the basis for running a two-way mixed model ANOVA, from which descriptors of FA, ME, and repeatability can be calculated (Palmer \& Strobeck 2003a). The aim of this paper is to provide an example of some of these, often unpublished, background statistics in asymmetry studies.

\section{Materials and methods}

\section{Sample}

A sample of 300 polar bear skulls from East Greenland (held at the Zoological Museum, University of Copenhagen), and 391 polar bear skulls from Svalbard (held at the Natural History Museum, University of Oslo) were examined. The skulls were collected during the period 1892-2004 (East Greenland, approx. $61^{\circ}-82^{\circ} \mathrm{N}$, $10^{\circ}-42^{\circ} \mathrm{W}$ ) and 1950-2004 (Svalbard, approx. $\left.74^{\circ}-81^{\circ} \mathrm{N}, 10^{\circ}-35^{\circ} \mathrm{E}\right)$. Many of the skulls were more or less damaged, and thus the entire range of measurements could not be taken on all skulls.

\section{Measurements}

The metric traits were measured on the right $(R)$ and left $(L)$ side of each skull, using digital callipers (Mitutoyo, Mitutoyo Corporation, Japan), to the nearest $0.04 \mathrm{~mm}$. The traits were measured twice on each skull, always by the same person, and never twice on the same day. Nine metric bilateral traits were measured in order to estimate the level of FA in the skulls (Table 1 and Fig. 1).

\section{Statistical analyses}

All statistical analyses were performed using 
SPSS (ver. 13.0). The significance level was set to $p=0.05$ unless other is specified.

\section{Outliers}

Possible outliers were identified visually from scatter plots as suggested by Palmer and Strobeck (2003b). The outliers were then tested and removed according to Grubbs' test (Grubbs 1969, Palmer \& Strobeck 2003b).

\section{FA, ME, and repeatability}

A two-way mixed model ANOVA (with $|R-L|$ as dependent variable, individual as random explanatory variable, side as fixed explanatory variable, and the interaction between individual and side) was applied to the replicate measurements in order to estimate the magnitude of FA relative to $\mathrm{ME}$. The $\mathrm{MS}_{\mathrm{SI}}$ (mean squares of the sides $\times$ individuals interaction) and $\mathrm{MS}_{\text {error }}$ (mean squares of the variance of the repeated measurements [error]) from the two-way mixed model ANOVA were furthermore used to estimate FA excluding ME in mm (FA10a), $\mathrm{MS}_{\text {error }}$ as a percentage of $\mathrm{MS}_{\mathrm{SI}}(\mathrm{ME} 3)$, repeatability (ME5), average difference between the repeated measurements (in mm)(ME1), FA including ME (in mm) (FA4a), ME1 as a percentage of FA4a, and FA1 mean \pm SE (the FA index $(|R-L|)$ used throughout the study (in mm) (see Palmer 1994, Palmer \& Strobeck 2003a, 2003b)).

\section{Results}

\section{Outliers}

A total of 126 measurements ( $R$ and $L$ ) were excluded from the statistical analysis. This corresponds to $2.0 \%$ of all measurements taken.

\section{FA, ME, and repeatability}

ME was found to be smaller than FA in all nine traits (Table 2). FA10a gives the measured FA $(|R-L|)$, excluding $\mathrm{ME}$, in $\mathrm{mm}$, and ranged between 0.14 and $4.46 \mathrm{~mm}$. The error variance contributed from $0.34 \%$ to $13.12 \%$ of the total variance between sides (ME3), except for Lp4 with $28.77 \%$. The generally low values of ME3 were reflected in the high repeatability (ME5) of the traits, which ranged between $77 \%$ and $99 \%$, except for trait Lp4 with 55\%. Expressed in another way, the average difference between the repeated measurements (ME1) made up between $5.85 \%$ and $53.64 \%$ of FA4a (FA including ME, in $\mathrm{mm}$ ). FA10a (FA excluding ME) was always lower than FA4a (FA including ME). The differ-

Table 1. Definition of the nine metric traits measured on skulls of East Greenland and Svalbard polar bears (Ursus maritimus).

\begin{tabular}{ll}
\hline Trait & Definition \\
\hline $\begin{array}{l}\text { Skull } \\
\text { OPF } \\
\text { CBL }\end{array}$ & $\begin{array}{l}\text { Maximal distance between the opistokranion and the postorbital process of the frontal bone. } \\
\text { Condylobasal length. The maximal distance between the anterior margin of the alveole of the 1st } \\
\text { incisor and the anterior margin of the occipital condyles. }\end{array}$ \\
P4-M2 & $\begin{array}{l}\text { Length from the anterior margin of the 4th premolar to the posterior margin of the 2nd molar. } \\
\text { L-M2 }\end{array}$ \\
I1-M2 & $\begin{array}{l}\text { Length from the anterior of the alveole of the canine, to the posterior of the alveole of the } 2 n d \text { molar. } \\
\text { molar. }\end{array}$ \\
POH & $\begin{array}{l}\text { Postorbital height. The minimal distance between the postorbital process of the frontal bone and } \\
\text { the frontal process of the zygomatic arch. }\end{array}$ \\
Lower jaw & $\begin{array}{l}\text { Length of the 4th premolar of the lower jaw. } \\
\text { Lp4 }\end{array}$ \\
ML & $\begin{array}{l}\text { Mandible length. The maximal distance between the anterior margin of the mandibular symphysis } \\
\text { and the posterior margin of the angular process. }\end{array}$ \\
MH & $\begin{array}{l}\text { Mandible height. The maximal distance between the margin of the angular process and the } \\
\text { coronoid process. }\end{array}$ \\
\hline
\end{tabular}




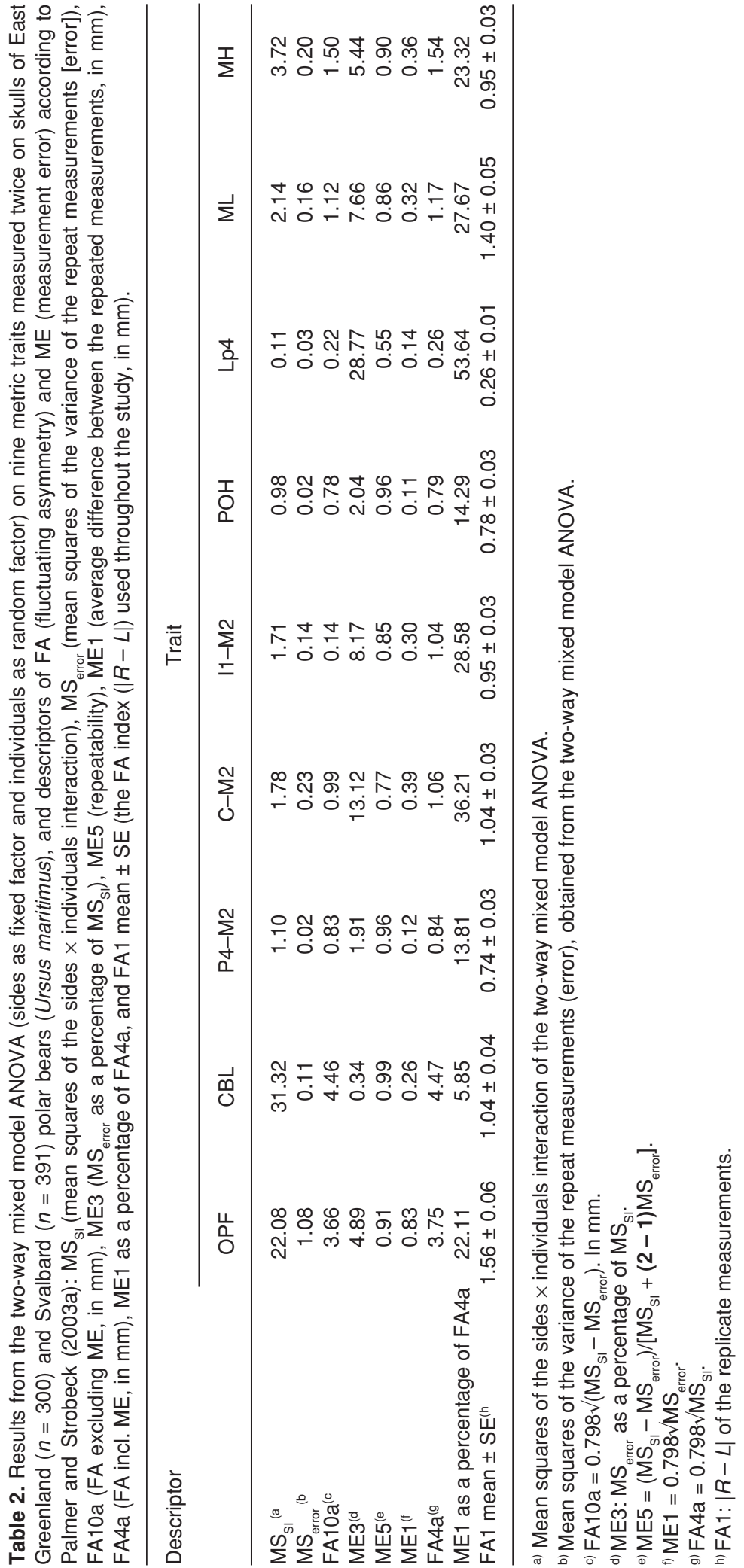


ence between these two indices represents the contribution ME made to the FA. FA differed between traits, but also varied depending on how it was computed. Estimates derived from variances (FA10a and FA4a) generally suggested greater FA variation among traits than the estimate derived from the mean absolute deviation (FA1) (Palmer \& Strobeck 2003b).

\section{Discussion}

\section{Outliers}

In this study, $2.0 \%$ of the FA data were identified and treated as outliers. In comparison, Ahtiainen et al. (2003) identified $2.1 \%$ of their FA data as outliers, and of the data from Crespi and Vanderkist (1997), Palmer and Strobeck (2003b) identified $5.7 \%$ as outliers.

\section{FA, ME, and repeatability}

For every trait measured, ME was found to be smaller than the FA. The magnitude of FA generally increased with trait size, as expected (Palmer \& Strobeck 1986, Leung 1998).

FA for each trait amounted to roughly $0.1 \%$ $3.0 \%$ of the average size of the corresponding trait (Table 2), which is on average slightly higher than the 1\% predicted by Palmer (1996). ME1 gives the measurement error for each trait, but is quite dependent on trait size. When comparing ME between traits, the dimensionless estimator ME1 as a percentage of FA4a is probably better suited. The premolar of the lower jaw (Lp4) appears to be a poor trait for measuring FA, with ME making up 53.6\% of the FA (FA4a). On the other hand, the ME of the second tooth trait (P4-M2) only made up $13.8 \%$ of the FA (FA4a), despite there being larger room for error here, as the individual teeth were not always very solidly sat in their position in the jaw and hence could be rocked in all directions. Perhaps the one premolar (Lp4) is subjected to a different kind of wear than the row (P4-M2) (Sonne et al. 2007), which makes its edges harder to define. The comparatively high error rates of traits C-M2 (36.2\%) and I1-M2 $(28.6 \%)$ could be attributed to dif- ficulty in determining the border of the alveoles, especially the alveole of the canine tooth. The values of ME1 as a percentage of FA4a were all within the same range as found for the traits in Crespi and Vanderkist (1997) as calculated by Palmer and Strobeck (2003b), and those reported by Palmer and Strobeck (1986).

The repeatability (ME5) of the traits was inversely proportional to ME1 as a percentage of FA4a. The harder the traits were to replicate in measurements, the higher the ME. Five of the nine traits had a repeatability of $90 \%$ or more (traits OPF, CBL, P4-M2, POH, and MH). Trait Lp4 had the lowest repeatability (55\%), which supports the notion of this as a poor trait for FA measurements. The repeatability of the remaining traits $(\mathrm{ML}, \mathrm{I} 1-\mathrm{M} 2$, and $\mathrm{C}-\mathrm{M} 2)$ ranged between $77 \%$ and $86 \%$. When compared with the results of repeatability in the traits measured by Crespi and Vanderkist (1997) (four traits, range 38\%-99.5\%) as calculated by Palmer and Strobeck (2003b), and the results of repeatability reported in Kark (2001) (two traits, range 91\%-99\%), Pertoldi et al. (1997) (four traits, range 96.8\%-98.2\%) and Pertoldi et al. (2000) (two traits, range $89 \%-93 \%$ ), the results of the present study seem acceptable.

\section{Acknowledgements}

The Zoological Museum, University of Copenhagen, Denmark and the Natural History Museum, University of Oslo, Norway are acknowledged for providing access to their collections of polar bear skulls.

\section{References}

Ahtiainen, J. J., Alatalo, R. V., Mappes, J. \& Vertainen, L. 2003: Fluctuating asymmetry and sexual performance in the drumming wolf spider Hygrolycosa rubrofasciata. - Annales Zoologici Fennici 40: 281-292.

Andersen, D. H., Pertoldi, C., Loeschcke, V. \& Scali, V. 2006: Developmental instability, hybridization and heterozygosity in stick insects of the genus Bacillus (Insecta; Phasmatodea) with different modes of reproduction. - Biological Journal of the Linnean Society 87: 249-259.

Bechshøft, T. Ø., Wiig, Ø., Sonne, C., Rigét, F. F., Dietz, R., Letcher, R. J. \& Muir, D. C. G. 2008: Temporal and spatial variation in metric asymmetry in skulls of polar bears (Ursus maritimus) from East Greenland and Sval- 
bard. - Annales Zoologici Fennici 45: 15-31.

Blagojevic, J. \& Vujosevic, M. 2004: B chromosomes and developmental homeostasis in the yellow-necked mouse, Apodemus flavicollis (Rodentia, Mammalia): effects on non-metric traits. - Heredity 93: 249-254.

Borrell, Y. J., Pineda, H., McCarthy, I., Vasquez, E., Sanchez, J. A. \& Lizana, G. B. 2004: Correlations between fitness and heterozygosity at allozyme and microsatellite loci in the Atlantic salmon, Salmo salar L. - Heredity 92: 585-593.

Crespi, B. J. \& Vanderkist, B. A. 1997: Fluctuating asymmetry in vestigial and functional traits of a haploid insect. - Heredity 79: 624-630.

Gibbs, M. \& Breuker, C. 2006: Effect of larval-rearing density on adult life-history traits and developmental stability of the dorsal eyespot pattern in the speckled wood butterfly, Pararge aegeria. - Entomologia Experimentalis et Aplicata 18: 41-47.

Green, C. C. \& Lochmann, S. E. 2006: Fluctuating asymmetry and condition in golden shiner (Notemigonus crysoleucas) and channel catfish (Ictalurus punctatus) reared in sublethal concentrations of isopropyl methylphosphonic acid. - Environmental Toxicology and Chemistry 25: 58-64.

Grubbs, F. E. 1969: Procedures for detecting outlying observations in samples. - Technometrics 11: 1-21.

Kark, S. 2001: Shifts in bilateral asymmetry within a distribution range: the case of the Chukar partridge. - Evolution 55: 2088-2096.

Leung, B. 1998: Correcting for allometry in studies of fluctuating asymmetry and quality within samples. Proceedings of the Royal Society of London B 265: 1623-1629.

Mazzi, D., Künzler, R. \& Bakker, T. C. M. 2003: Female preference for symmetry in computer-animated threespined sticklebacks, Gasterosteus aculeatus. - Behavioral Ecology and Sociobiology 54: 156-161.

Merilä, J. \& Björklund, M. 1995: Fluctuating asymmetry and measurement error. - Systematic Biology 44: 97-101.

Møller, A. P. 2006: A review of developmental instability, parasitism and disease infection, genetics and evolution. - Infection Genetics and Evolution 6: 133-140.

Møller, A. P. \& Swaddle, J. P. 1997: Asymmetry, developmental stability, and evolution. - Oxford University Press, Oxford.

Palmer, A. R. 1994: Fluctuating asymmetry analyses: A primer. - In: Markow, T. A. (ed.), Developmental instability: its origins and evolutionary implications: $335-$ 364. Kluwer, Dordrecht.

Palmer, A. R. 1996: Waltzing with asymmetry. — BioScience 46: 518-532.

Palmer, A. R. \& Strobeck, C. 1986: Fluctuating asymmetry: Measurement, analysis, patterns. - Annual review of Ecology and Systematics 17: 391-421.

Palmer, A. R. \& Strobeck, C. 2003a: Fluctuating asymmetry analyses revisited. - In: Polak, M. (ed.), Developmental instability. Causes and consequences: 279-319. Oxford University Press, Oxford.

Palmer, A. R. \& Strobeck, C. 2003b: Fluctuating asymmetry analysis: a step-by-step example [Electronic Appen- dix V in: Fluctuating asymmetry analyses revisited]. - In: Polak, M. (ed.), Developmental instability. Causes and consequences: 279-319. Oxford University Press, Oxford.

Pelabon, C., Hansen, T. F., Carlson, M. L. \& Armbruster, W. S. 2006: Patterns of asymmetry in the twining vine Dalechampia scandens (Euphorbiaceae): Ontogenetic and hierarchical perspectives. - New Phytologist 170: $65-74$.

Pertoldi, C., Loeschcke, V., Madsen, A. B. \& Randi, E. 1997: Developmental stability in the Eurasian Otter (Lutra lutra) in Denmark. - Annales Zoologici Fennici 34: 187-196.

Pertoldi, C., Loeschcke, V., Braun, A., Madsen, A. B. \& Randi, E. 2000: Craniometrical variability and developmental stability. Two useful tools for assessing the population viability of Eurasian otter (Lutra lutra) populations in Europe. - Biological Journal of the Linnean Society 70: 309-323.

Petavy, G., David, J. R., Debat, V., Pertoldi, C. \& Moreteau, B. 2006: Phenotypic and genetic variability of sternopleural bristle number in Drosophila melanogaster under thermal stress: developmental instability and anti-symmetry. - Evolutionary Ecology Research 8: 149-167.

Pravosudov, V. V. \& Kitaysky, A. S. 2006: Effects of nutritional restrictions during post-hatching development on adrenocortical function in western scrub-jays (Aphelocoma californica). - General and Comparative Endocrinology 145: 25-31.

Siegel, M. I., Doyle, W. J. \& Kelley, C. 1977: Heat stress, fluctuating asymmetry and prenatal selection in the laboratory rat. - American Journal of Physical Anthropology 46: 121-126.

Sonne, C., Rigét, F. F., Dietz, R., Wiig, Ø., Kirkegaard, M. \& Born, E. W. 2007: Skull pathology in East Greenland and Svalbard polar bears (Ursus maritimus) during 1892 to 2002 in relation to organochlorine pollution. - Science of the Total Environment 372: 554-561.

Stige, L. C. 2004: Fluctuating asymmetry: A marker of individual genetic or phenotypic quality? - Ph.D. thesis, Department of Biology, University of Oslo.

Valetsky, A. V., Dmitrieva, I. L., Krushinskaya, N. L. \& Zakharov, V. M. 1997: Social stress impact on developmental stability of laboratory rat Rattus norvegicus. - Acta Theriologica Suppl. 4: 27-32.

Vilisics, F., Solymos, P. \& Hornung, E. 2005: Measuring fluctuating asymmetry of the terrestrial isopod Trachelipus rathkii (Crustacea: Isopoda, Oniscidea). - European Journal of Soil Biology 41: 85-90.

Voigt, C. C., Heckel, G. \& Mayer, F. 2005: Sexual selection favours small and symmetric males in the polygynous greater sac-winged bat Saccopteryx bilineata (Emballonuridae, Chiroptera). - Behavioral Ecology and Sociobiology 57: 457-464.

Zakharov, V. M. 1992: Population phenogenetics: Analysis of developmental stability in natural populations. - Acta Zoologica Fennica 191: 7-30.

Zakharov, V. M. \& Yablokov, A. V. 1990: Skull asymmetry in the Baltic grey seal: Effects of environmental pollution. - Ambio 19: 266-269. 
Zakharov, V. M., Demin, D. V., Baranov, A. S., Borisov, V. I., Valetsky, A. V. \& Sheftel, B. I. 1997: Developmental stability and population dynamics of shrews Sorex in central Siberia. - Acta Theriologica Suppl. 4: 41-48. 